\title{
Rational Design of Materials with Extreme Negative Compressibility: Selective Soft-Mode Frustration in $\mathrm{KMn}\left[\mathrm{Ag}(\mathrm{CN})_{2}\right]_{3}$
}

\author{
Andrew B. Cairns, ${ }^{\dagger}$ Amber L. Thompson, ${ }^{\dagger}$ Matthew G. Tucker, ${ }^{\ddagger}$ Julien Haines, ${ }^{\S}$ and \\ Andrew L. Goodwin ${ }^{\star} \dagger$
}

\begin{abstract}
${ }^{\dagger}$ Department of Chemistry, Inorganic Chemistry Laboratory, University of Oxford, South Parks Road, Oxford OX1 3QR, U.K.; ${ }^{*} I S I S$ Facility, Rutherford Appleton Laboratory, HSIC, Didcot OX11 OQX, U.K.; ${ }^{\S}$ Institut Charles Gerhardt, UMR CNRS 5253, Université Montpellier II, Place E. Bataillon cc1504, 34095, Montpellier Cedex 05, France.
\end{abstract}

RECEIVED DATE May 27, 2011; E-mail: andrew.goodwin@chem.ox.ac.uk

The vast majority of materials shrink under increasing pressure. However it has been known for some time that in certain structure types volume reduction can be achieved by actually expanding the crystal lattice along specific directions. ${ }^{1-3}$ This effect, termed negative linear compressibility (NLC), is a remarkably rare phenomenon. Only a dozen or so examples are known, and in most of these the effect is relatively weak..$^{1,45}$ On the macroscopic scale the phenomenon of NLC is not necessarily counterintuitive: both trellis fencing and wine racks are "packed away" by pulling in one direction. The challenge for the materials chemist is to engineer this same functionality on the atomic scale such that it becomes an intrinsic material property to be exploited appropriately. NLC is of strong practical interest in, for example, the development of highly sensitive pressure detectors for seismic, sonar and aircraft applications, as components of essentially incompressible composites, and in "smart" materials for next-generation body armour. ${ }^{1,2,6}$ For all such applications, the primary objective is to develop materials that exhibit the strongest possible NLC effect over the largest possible pressure range.

Quantitative comparison of NLC amongst different materials is made possible via the isothermal compressibility, defined as the relative rate of change of dimension with pressure, $K_{\ell}=-$ $(\partial \ln \ell / \partial p)_{T}$, measured at constant temperature. For crystalline materials the value of $K$ normally lies between $5 \mathrm{TPa}^{-1}$ (stiffer, less compressible) and $50 \mathrm{TPa}^{-1}$ (softer, more compressible). ${ }^{7}$ In contrast, NLC materials have $K<0 \mathrm{TPa}^{-1}$; but until very recently the most negative values observed were just -2 and $-1.2 \mathrm{TPa}^{-1}$ for $\alpha$ cristobalite structured $\mathrm{BAsO}_{4}$ and trigonal $\mathrm{Se}$, respectively. ${ }^{8,9}$

$\mathrm{We}^{4}$ and others ${ }^{5}$ have since shown that stronger NLC can be found in framework structures that show very anisotropic negative thermal expansion (NTE) behaviour-i.e. on heating, their structures contract in one or more directions. There is actually no thermodynamic requirement that NTE and NLC coexist, ${ }^{10}$ but what is emerging is an empirical interdependence of the two phenomena. So, for example, the framework material $\mathrm{Ag}_{3}\left[\mathrm{Co}(\mathrm{CN})_{6}\right]$ shows "colossal" NTE along the $c$-axis of its trigonal crystal lattice ${ }^{11}$ NLC is found in the same direction with $K_{c}=-75 \mathrm{TPa}^{-1}$ until a phase transition at $0.19 \mathrm{GPa}$, and $K_{c}=-5 \mathrm{TPa}^{-1}$ thereafter. ${ }^{4}$ Methanol monohydrate also exhibits strong NTE and NLC along a shared axis, in this case with $K_{a}=-3.1 \mathrm{TPa}^{-1}$. There are, however, fundamental reasons why these two "new-generation" NLC materials are unlikely to be suitable for practical application. Methanol monohydrate is stable only at temperatures below $160 \mathrm{~K} .{ }^{5}$ In $\mathrm{Ag}_{3}\left[\mathrm{Co}(\mathrm{CN})_{6}\right]$, the $0.19 \mathrm{GPa}$ phase transition actually involves a significant volume collapse and hence, while the linear compressibilities measured on either side of the transition are certainly negative, the average compressibility taken over a pressure range $0-2 \mathrm{GPa}$ (typical for many practical applications ${ }^{12}$ ) is actually quite strongly positive: $K=+41 \mathrm{TPa}^{-1}$.

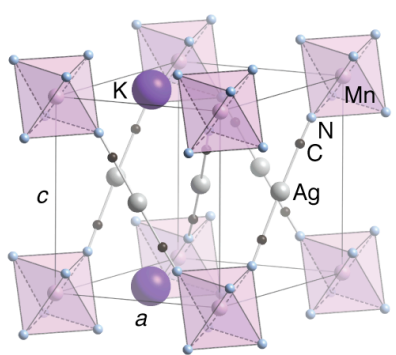

(a)

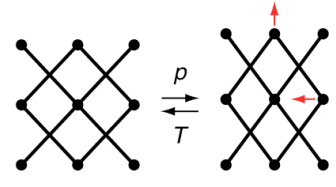

(b)

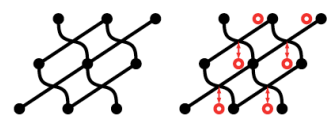

(c)

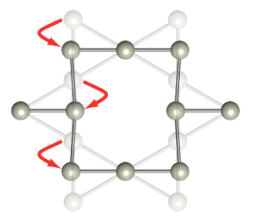

(d)

(e)

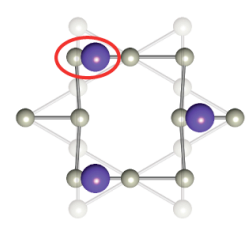

Figure 1. (a) Crystal structure of $\mathrm{KMn}\left[\mathrm{Ag}(\mathrm{CN})_{2}\right]_{3}:\left[\mathrm{MnN}_{6}\right]$ octahedra are connected via almost-linear $\mathrm{NC}-\mathrm{Ag}-\mathrm{CN}$ units, with $\mathrm{K}^{+}$ions positioned above and below alternating $\mathrm{Ag}_{3}$ Kagome triangles. (b) Schematic representations of the "wine-rack" NTE/NLC mechanism. (c) In $\mathrm{Ag}_{3} \mathrm{Co}(\mathrm{CN})_{6}$ NLC is destroyed by shear-induced framework collapse at $0.19 \mathrm{GPa}$ (left); this mechanism is frustrated in $\mathrm{KMn}\left[\mathrm{Ag}(\mathrm{CN})_{2}\right]_{3}$ via incorporation of extra framework ions (open red circles; right). (d) Rearrangement of the $\mathrm{Ag}$ Kagome sublattice, viewed here down the $c$-axis, couples to framework shear in $\mathrm{Ag}_{3}\left[\mathrm{Co}(\mathrm{CN})_{6}\right]$. (e) These displacements would give unphysical $\mathrm{Ag}^{+} \ldots \mathrm{K}^{+}$distances in $\mathrm{KMn}\left[\mathrm{Ag}(\mathrm{CN})_{2}\right]_{3}$; the soft mode responsible is stiffened and the phase transition responsible for destroying NLC is avoided.

Here we study $\mathrm{KMn}\left[\mathrm{Ag}(\mathrm{CN})_{2}\right]_{3}[$ Fig. $1(\mathrm{a})],{ }^{13}$ which we show to exhibit the strongest persistent NLC effect yet reported: $K=-$ 12.0(8) $\mathrm{TPa}^{-1}$ over the entire pressure range $0<p<2.2 \mathrm{GPa}$. Our motivation for choosing this particular material comes from trying to retain the key structural motifs responsible for extreme NTE/NLC behaviour in $\mathrm{Ag}_{3}\left[\mathrm{Co}(\mathrm{CN})_{6}\right]$ whilst eliminating those aspects associated with its volume collapse at $0.19 \mathrm{GPa}$. So it is intentional that the structure of $\operatorname{KMn}\left[\operatorname{Ag}(\mathrm{CN})_{2}\right]_{3}$, which has been reported previously, ${ }^{14}$ is closely related to that of $\mathrm{Ag}_{3}\left[\mathrm{Co}(\mathrm{CN})_{6}\right] .{ }^{15}$ In particular, both share the motifs responsible for extreme NTE/NLC: an ultraflexible cyanide lattice whose dimensions are determined by low-energy $\mathrm{Ag}^{+} \ldots \mathrm{Ag}^{+}$"argentophilic" interactions [Fig. 1(b)]. ${ }^{11,16}$ The key modification is the inclusion of $\mathrm{K}^{+}$ions within cavities of the dicyanometallate framework, lowering the crystal symmetry from $P-31 \mathrm{~m}$ to $P 312 .{ }^{17}$ Because $\mathrm{K}^{+}$is not covalently bound to the framework, we anticipated structural flexibility - and hence NTE/NLC behaviour-would largely be retained. Indeed in a systematic study of a number of isostructural $\mathrm{KM}^{\mathrm{II}}\left[\mathrm{A}^{\mathrm{I}}(\mathrm{CN})_{2}\right]_{3}$ materials, Korčok et al. observed retention of strong anisotropic NTE throughout the family. ${ }^{16}$ However, by 
virtue of its interaction with the Kagome sublattice of $\mathrm{Ag}^{+}$ions, $\mathrm{K}^{+}$might be expected to influence strongly the existence of a high-pressure phase transition. Central to this idea is the observation that the shear instability responsible for volume collapse in $\mathrm{Ag}_{3}\left[\mathrm{Co}(\mathrm{CN})_{6}\right]$ is coupled to a translation of two thirds of the $\mathrm{Ag}^{+}$ ions to a site that in $\mathrm{KMn}\left[\mathrm{Ag}(\mathrm{CN})_{2}\right]_{3}$ would result in a very short $\mathrm{K}^{+}$... $\mathrm{Ag}^{+}$contact ( $c$ a $3.6 \AA$, cf. $4.8 \AA$ in the native compound) [Fig. 1(c,d)]. ${ }^{4}$ Our hope therefore was that the presence of $\mathrm{K}^{+}$ions would selectively stiffen the soft-mode responsible for a pressureinduced phase transition, whilst leaving the low-energy modes that drive NTE and NLC essentially undamped.

Measurements of the temperature-dependent (100-300 K) structure and unit cell parameters for $\mathrm{KMn}\left[\mathrm{Ag}(\mathrm{CN})_{2}\right]_{3}$ were performed using single crystal X-ray diffraction. ${ }^{16}$ The coefficients of thermal expansion $\alpha_{\ell}=(\partial \ln \ell / \partial T)_{p}$ extracted from these measurements were $\alpha_{a}=+61(2) \mathrm{MK}^{-1}$ and $\alpha_{c}=-60(3) \mathrm{MK}^{-1}$, reflecting strong positive thermal expansion perpendicular to the trigonal cell axis and strong NTE parallel to this axis; these values are similar in magnitude to those reported for $\mathrm{KCd}\left[\mathrm{Ag}(\mathrm{CN})_{2}\right]_{3}$ (+75 and $65 \mathrm{MK}^{-1}$, respectively), ${ }^{18}$ and about half as large as the "colossal" values of $\mathrm{Ag}_{3}\left[\mathrm{Co}(\mathrm{CN})_{6}\right]$ itself $\left(+144(9)\right.$ and $\left.-126(4) \mathrm{MK}^{-1}\right) .^{11,18}$ Consequently, the presence of $\mathrm{K}^{+}$ions does not fundamentally affect framework flexibility in $\mathrm{KMn}\left[\mathrm{Ag}(\mathrm{CN})_{2}\right]_{3}$.

In contrast, we do find evidence that the $\mathrm{Ag}^{+}$positions and displacements are influenced by the presence of extra-framework $\mathrm{K}^{+}$. First, the Kagome lattice of $\mathrm{Ag}^{+}$ions is distorted such that $\mathrm{Ag}_{3}$ triangles above or below $\mathrm{K}^{+}$ions are about $12 \%$ larger than those above or below vacant sites. Second, the thermal derivative $\mathrm{d} U_{\text {eq }} / \mathrm{d} T$ of the Ag displacement parameter is about $15 \%$ lower in $\mathrm{KMn}\left[\mathrm{Ag}(\mathrm{CN})_{2}\right]_{3}$ than in $\mathrm{Ag}_{3}\left[\mathrm{Co}(\mathrm{CN})_{6}\right]$ and $\mathrm{Ag}_{3}\left[\mathrm{Fe}(\mathrm{CN})_{6}\right] .^{11,19}$ This value is a crude measure of the energy of $\mathrm{Ag}$ displacement modes (large $\mathrm{d} U_{\mathrm{eq}} / \mathrm{d} T$ indicating low energy). ${ }^{20}$
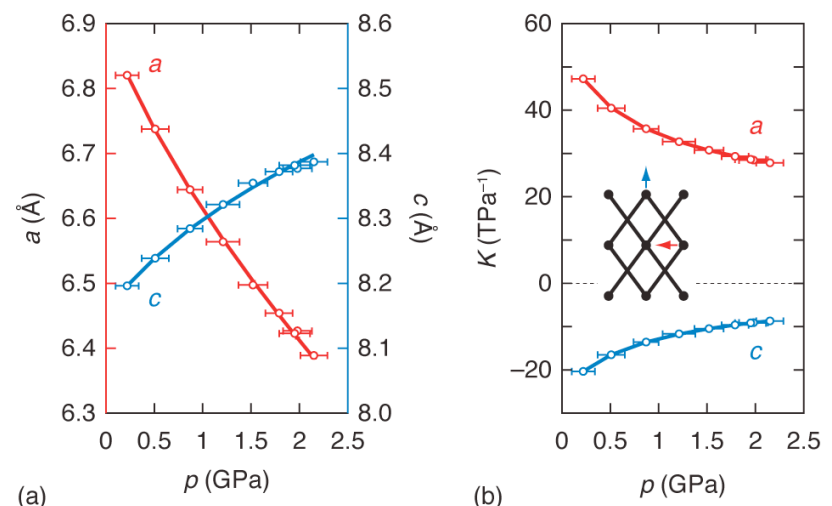

Figure 2. (a) Pressure-dependence of the lattice parameters of $\mathrm{KMn}\left[\mathrm{Ag}(\mathrm{CN})_{2}\right]_{3}$ determined using time-of-flight neutron powder diffraction, and (b) compressibilities extracted via an empirical fit (bold lines in (a)) as described in the text. Negative compressiblity along the $c$-axis is evident in the increase in the value of $c$ with increasing pressure.

In order to investigate the pressure-dependent behaviour of $\mathrm{KMn}\left[\mathrm{Ag}(\mathrm{CN})_{2}\right]_{3}$, we performed time-of-flight neutron powder diffraction measurements across the pressure range $0.2<p<$ $2.2 \mathrm{GPa}$ using the WISH diffractometer at ISIS. ${ }^{21,22}$ All data could be accounted for using a structural model based on the P312 cell of the ambient phase. We found no evidence for any structural phase transitions throughout the pressure range studied. Lattice parameters were extracted from the powder neutron diffraction data using the GSAS Rietveld refinement package, ${ }^{23}$ a plot of these values is given in Fig. 2(a). The absence of discontinuities also reflects the persistence of the ambient phase throughout the pressure range studied. Linear compressibilities were determined via error-weighted fits to the lattice parameters using an empirical expression of the form $\ell=\ell_{0}+\lambda\left(p-p_{\mathrm{c}}\right)^{v}\left[\right.$ Fig. 2(b)]. ${ }^{4}$ The mean values we obtain are $K_{a}=+33.2(13) \mathrm{TPa}^{-1}$ and $K_{c}=-12.0(8) \mathrm{TPa}^{-1}$. To the best of our knowledge, this is the strongest NLC effect ever reported over such a large pressure range. Importantly NLC in $\mathrm{KMn}\left[\mathrm{Ag}(\mathrm{CN})_{2}\right]_{3}$ is now similar in magnitude to the positive compressibilities of "normal" materials, suggesting that effectively incompressible composites might genuinely be attainable.

Despite the absence of any necessary link between NLC and NTE, our results for $\mathrm{KMn}\left[\mathrm{Ag}(\mathrm{CN})_{2}\right]_{3}$ reinforce the emerging strategy of looking for extreme NLC in compounds that exhibit anisotropic NTE. Consequently, NLC might be expected to recur for much of the $\mathrm{MM}^{\prime}\left[\mathrm{A}(\mathrm{CN})_{2}\right]_{3}$ family $\left(\mathrm{M}=\right.$ alkali metal, $\mathrm{M}^{\prime}=$ divalent transition-metal cation, and $\mathrm{A}=$ group 11 monocation). ${ }^{14,18,24,25}$ For all such materials there will be a risk that the very flexibility responsible for NTE will also favour low-pressure soft-mode instabilities associated with volume collapse. Our key result here has been to show how relatively simple chemical modifications can frustrate such a collapse mechanism whilst preserving the geometric flexibility that results in extreme NLC.

Acknowledgments. This work was supported by the EPSRC (UK) under grant EP/G004528/2, STFC (WISH diffractometer), and the ANR under grant ANR-09-BLAN-0018-01. The authors are grateful to L. Chapon (STFC) for technical support and to $\mathrm{S}$. Klotz for providing the boron nitride anvil used in this work.

Supporting Information Available: Synthesis, crystallographic methods, single-crystal X-ray structural information, CIF files, variable pressure neutron powder diffraction data and GSAS fits, temperature- and pressure-dependent lattice parameter values.

\section{References}

(1) Baughman, R. H.; Stafström, S.; Cui, C.; Dantas, S. O. Science 1998, $279,1522-1524$.

(2) Baughman, R. H. Nature 2003, 425, 667

(3) Grima, J. N.; Attard, D.; Gatt, R. Science 2011, 331, 687-688.

(4) Goodwin, A. L.; Keen, D. A.; Tucker, M. G. Proc. Natl. Acad. Sci. U.S.A. 2008, 105, 18708-18713.

(5) Fortes, A. D.; Suard, E.; Knight, K. S. Science 2011, 331, 742-746.

(6) Evans, K. E.; Alderson, A. Adv. Mater. 2000, 12, 617-628

(7) Newnham, R. E. Properties of Materials (Oxford Univ Press, Oxford, 2005).

(8) McDann, D. R.; Cartz, L.; Schmunk, R. E.; Harker, Y. D. J. Appl. Phys. 1972, 43, 1432-1436.

(9) Haines, J.; Chateau, C.; Léger, J. M.; Bogicevic, C.; Hull, S.; Klug, D. D.; Tse, J. S. Phys. Rev. Lett. 2003, $91,015503$.

(10) Munn, R.W. J. Phys. C 1972, 5, 535-542.

(11) Goodwin, A. L.; Calleja, M.; Conterio, M. J.; Dove, M. T.; Evans, J. S. O.; Keen, D. A.; Peters, L.; Tucker, M. G. Science 2008, 319, 794-797.

(12) Chapman, K. W.; Halder, G. J.; Chupas, P. J. J. Am. Chem. Soc. 2009, $131,17546-17547$.

(13) $\mathrm{KMn}\left[\mathrm{Ag}(\mathrm{CN})_{2}\right]$ was prepared by slow diffusion of aqueous solutions of $\mathrm{Mn}\left(\mathrm{NO}_{3}\right)_{2} .6 \mathrm{H}_{2} \mathrm{O}\left(0.039 \mathrm{M}\right.$, Aldrich) and $\mathrm{KAg}(\mathrm{CN})_{2}(0.063 \mathrm{M}$, Aldrich). After $14 \mathrm{~d}$, the product was filtered, washed $\left(\mathrm{H}_{2} \mathrm{O}\right)$, and dried $\left(50{ }^{\circ} \mathrm{C}\right.$, $24 \mathrm{~h})$ to afford the product as transparent colourless triangular plates.

(14) Geiser, U.; Schlueter, J. A. Acta Crystallogr., Sect. C 2003, 59, i21-i23.

(15) Pauling, L.; Pauling, P. Proc. Natl. Acad. Sci., U.S.A. 1968, 60, 362-367.

(16) Data were collected using a Nonius KappaCCD diffractometer ${ }^{26}$ We used SIR92 ${ }^{27}$ within CRYSTALS ${ }^{28}$ for structure solution (see SI).

(17) $\mathrm{CN}$ orientations also differ between the two compounds. ${ }^{14,1}$

(18) Korčok, J. L.; Katz, M. J.; Leznoff, D. B. J. Am. Chem. Soc. 2009, 131, 4866-4871

(19) Goodwin, A. L.; Keen, D. A.; Tucker, M. G.; Dove, M. T.; Peters, L.; Evans, J. S. O. J. Am. Chem. Soc. 2008, 130, 9660-9661.

(20) Goodwin, A. L.; Kepert, C. J. Phys. Rev. B. 2005, 71, 140301.

(21) Chapon, L.; Manuel, P.; Radaelli, P.; Benson, C.; Perrott, L.; Ansell, S.; Rhodes, N.; Raspino, D.; Duxbury, D.; Spill, E.; Norris, J. Neutron News 2011, 22(2), 22-25.

(22) This experiment is the first high-pressure experiment on the WISH diffractometer, performed as a test experiment within a small window of commissioning beamtime $(\sim 6 \mathrm{~h})$. The pressure range over which useable data could be collected was constrained by available experiment time, and not by decomposition or transformation of the title compound.

(23) Larson, A. C.; von Dreele, R. B. General structure analysis system (GSAS). Los Alamos National Laboratory Report LAUR 86-748, 1994.

(24) Hoskins, B. F.; Robson, R.; Scarlett, V. Y. J. Chem. Soc., Chem. Commun. 1994, 2025-2026.

(25) Abrahams, S. C.; Bernstein, J. L.; Liminga, R.; Eisenmann, E. T. J. Chem. Phys. 1980, 73, 4585-4590.

(26) Otwinowski, Z.; Minor, W. Meth. Enz.: Macr. Cryst. A 1997, 276, 307.

(27) Altomare, A. et al. J. Appl. Crystallogr. 1994, 27, 435.

(28) Betteridge, P. W.; Carruthers, J. R.; Cooper, R. I.; Prout, K.; Watkin, D. J. J. Appl. Cryst. 2003, 36, 1487. 

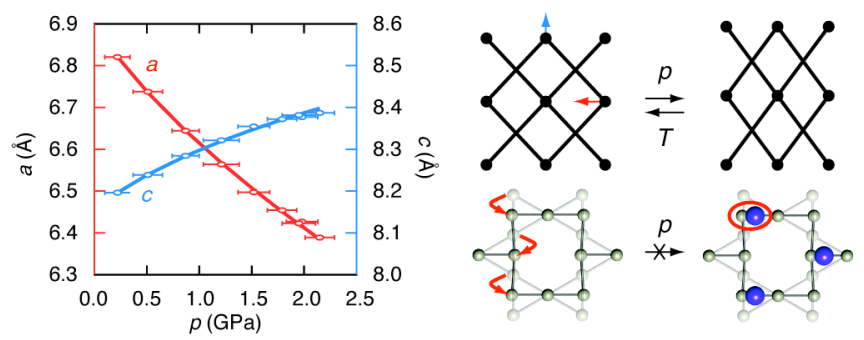

We show that $\mathrm{KMn}\left[\mathrm{Ag}(\mathrm{CN})_{2}\right]_{3}$ exhibits the strongest negative linear compressibility (NLC) effect over the largest pressure range yet observed. Variable pressure neutron powder diffraction measurements reveal that its crystal lattice expands along the $c$ axis of its trigonal cell under increasing hydrostatic pressure, whilst contracting along the $a$ axis. This corresponds to a "wine-rack"-like mechanism for NLC that we find also results in anisotropic negative thermal expansion (NTE) in the same material. Inclusion of extra-framework $\mathrm{K}^{+}$counterions has minimal effect on framework flexibility (and hence the magnitude of NTE/NLC) but selectively frustrates the soft phonon modes responsible for destroying NLC in the related material $\mathrm{Ag}_{3}\left[\mathrm{Co}(\mathrm{CN})_{6}\right]$. 